\title{
Impact of Child's Cancer on Family Life Case Study: Children with Cancer Newly admitted to the National Cancer Institute (NCI), Cairo University
}

\author{
Nevein Nagy \\ Institute of Statistical Studies and Research Department \\ Demographic and Biostatistics Cairo University \\ vena_3_49@hotmail.com \\ Mohamed Mostafe \\ Institute of Statistical Studies and Research Department \\ Demographic and Biostatistics Cairo University \\ dr_mohamed_most@yahoo.com \\ Hesham Makhlof \\ Institute of Statistical Studies and Research Department \\ Demographic and Biostatistics Cairo University \\ hhmakhlouf@gmail.com \\ Manar Moneer \\ Pro. National Cancer Institute, Cairo University \\ Department of Statistics and Epidemiology Cairo University \\ manar_monear@yahoo.com \\ Wael Zekry \\ Pro. National Cancer Institute, Cairo University \\ Department Children Section Cairo University \\ waelzekri@gmail.com
}

\begin{abstract}
The diagnosis of a family member with any disease certainly affects the family life in general. Hence, this study aims at exploring how the diagnosis of a child with cancer affects family life. Additionally, the study seeks to identify the extent to which the life of family can change when they have a child diagnosed with cancer. This study uses advanced statistical analysis through conducting a random sampling field study of (804) individuals, of which (402) were mothers of children diagnosed with cancer (as a case group), and (402) were mothers whose children's samples gave negative results when tested for cancer (as a control group). Through a Questionnaire Form designed to track the extent to which the lives of families covered by the two study samples (the case group and the control group) have changed, data were collected in 2015, the researcher used a number of indicators, which she believes to have an effect on family status, to compare the changes experienced by families in both groups. The 11 indicators used by the study measure the effects of having a child with cancer in each family individually. Results revealed significant differences in the values of indicators between the group having a child with cancer and the group whose children tested negative for cancer before and after diagnosis/examination. A composite indicator consisting of the previous indicators is developed using Factor Analysis, which calculated the said indicator based on four factors. These factors are then multiplied by their corresponding weights and aggregated into the new composite indicator(Family Status Indicator). The indicator was clustered using the K-Mean Cluster Analysis into 3 clusters, i.e. low, medium, and high. Conclusion: The child cancer has an impact on the Family Status indicator, demographics and socioeconomic determinants affect the Family Status indicator like (mother work and Education, Education of the father, Place of Residence,...etc.) after child examination or disease.
\end{abstract}


Keywords: Family Status Indicator (FSI), Childhood cancer rates, Child cancer deaths.

\section{Introduction}

In recent years, there has been a remarkable increase in the numbers of cancer cases worldwide, especially in developing countries where ignorance and pollution prevail. In Egypt, child cancer cases were 1665.119 in years 1999 to 2001 (MECC Monograph 2002), the Crude Age Standardized Incidence Rates of Childhood Cancer (per million) to all cancer male which are 171 and 114 for female (Amal S. Ibrahim \&other 2008). Mothers' reported their own and the child's quality of life (QOL) to be significantly lower than population norms. There were significant correlations between mothers' worries and their own and their ratings of the child's QOL and mothers' ratings of their own QOL correlated with their ratings of the child's QOL (Christine Eiser 2004). The ratio of Males to females was 1.8:1 among study patients with a median age of 8 years at diagnosis. Hematological malignancies represented $70.1 \%$ of the sample, with the highest proportion for ALL (52.2\%). Total QOL showed to be relatively low with mean value of 62.29 for the whole group. Subscales with least scores were for; worry (44.11), perceived physical appearance (50.6), and procedural anxiety (55.34). On the other hand, the best score was 75.98 for communication, followed by 72.63 for cognitive problems. The impacts of some medical and socio-demographic variables on QOL and its subscales were elicited in the results (Mohamed Fawzy \& Others 2013). The Ego-Resilience (ER) was positively correlated with children's QOL. Effortful Control (EC) showed a positive indirect effect on QOL through ER. Inclusion of potential correlates of pediatric QOL (e.g., parent neuroticism) did not change these and temperament and personality play significant roles in pediatric cancer patients' QOL. Assessing dispositional attributes early in treatment may help identify children at risk for poor QOL during and after treatment (Harper, Goodlett BD \& Others 2014).

There were significant relations between anti metabolite chemotherapeutics and feeling irritable and worrying $(\mathrm{p}=0.001, \mathrm{p}=0.030)$; vinkoalkaloid and numbness/tingling in hands/feet $(\mathrm{p}=0.043)$; anthracic lines and lack of energy and skin changes $(\mathrm{p}=0.021$, $\mathrm{p}=0.004)$; and corticosteroids and lack of appetite, nausea and sadness ( $\mathrm{p}=0.008$, $\mathrm{p}=0.009, \mathrm{p}=0.009$ ). Several symptoms such as feeling sad, worrying and feeling irritable caused a significant decrease in the total domain of quality of life scores $(p=0.034$, $\mathrm{p}=0.012, \mathrm{p}=0.010$, respectively). Chemotherapeutic drugs can cause symptoms that can seriously affect quality of life in children (Fatma TAS Arslan \& Others 2013). Quality of life refers to the social, emotional and physical outcomes of healthcare treatments as perceived by the children and adolescents with cancer. It has considerable changes in overall quality of life and dimensions in cancer patients (TAS and Y1lmaz, 2008; Trem olada et al., 2011, Hansson et al., 2013.

The child's perception of their Health-Related Quality of Life (HRQoL) was $66.0 \pm 13.3$ and parents' perception scored $60.3 \pm 15.0$. The agreement between self and proxy-report was moderate (strong association). Variables related to the child's age, gender, type of tumor, time elapsed since diagnosis and number of hospitalizations did not influence the differences between self and proxy-report (Luís Manuel Cunha Batalha \&Others 2015). 
According to (Claire Mc, Jeremy \& et al) the local lifestyle surveys are a cost-effective and appropriate mechanism for collecting detailed population measures of individual behaviors that impact on health, the following Key topic areas are identified to be addressed through the questionnaire: alcohol consumption, body mass index, dental health status, diet and nutrition, drug consumption, mental health, neighborhood perceptions, physical activity levels, prevalence of disease, self-reported general health, sexual health history and behavior, smoking status. A new questionnaire has been designed for the care of the child with cancer and their families before and after the diagnosis.

\section{Research Problem}

The child cancer impact on the Family Status studies are rarely found, most of the studies addressed only the Quality of Life. Steady and rapid increase in child cancer rates and child cancer deaths is definitely a major challenge that can affect the lives of families having the children with cancer. The study problem revolves around one question, that is: does the diagnosis of a child with cancer affect the status of their family? In other words, the study seeks to find the extent to which a family life changes when they have a child diagnosed with cancer.

\section{Study Objectives:}

The study aims at understanding how the diagnosis of a child with cancer may change family status. The study objectives are as follows:

1- Determine the effect of the diagnosis of a child with cancer on the status of a family and its changes.

2- What are the Demographic and Socio-economic, Determinants which have Impact on family status before and after child examination or disease?

\section{Hypotheses}

This study is based on the following hypotheses:

- A family status levels are considered a dependent variable which is a function within a group of independent variables represented by demographic and socioeconomic determinants.

- The diagnosis of a child with cancer affects the status of a family.

\section{Data Sources}

- The study relies on two main data sources as follows:

- A- First Source: outpatient clinics data found in records of patient admission in external clinics (NCI, Cairo University, 2009).

- $\quad$ B- Second Source: the field study was conducted using the following steps: 
The questionnaire form was designed in light of previous studies and results of focus group (10) and (20) in-depth interviews. The focus group and in-depth interviews were conducted.

The questionnaire form was designed in a manner ensuring the achievement of the study objectives which serve the study hypotheses testing.

a- $\quad$ A pre-test of the questionnaire form was conducted at the NCI through selecting a small group possessing the same characteristics of the control and case groups (pilot study applied for 50 cases).

b- The questionnaire form was modified in accordance with the pre-test results which showed that certain questions were not clear.

c- The validity and reliability of the questionnaire form were tested in preparation for following the actual data collection steps.

d- $\quad$ The questionnaire form was evaluated by expert evaluators.

e- The sampling frame (record of admitted individuals diagnosed with cancer record of admitted individuals not diagnosed with cancer, 2009) from which the samples shall be drawn was identified.

f- Approval of the finalized questionnaire form was obtained from the Central Agency for Public Mobilization and Statistics (CAPMAS).

g- The Ethics Committee at the NCI approved the use of the questionnaire form as well as the research proposal of the study.

h- The mother of children approved verbally to conduct the survey, most of them accepted to complete the survey but $2 \%$ refused to participate or to continue the survey which most of them lost their child.

i- $\quad$ Duration of the interview between 20-30 minutes.

\section{Identification of Target Population:}

1- Case Group: this group includes mothers of children (less than 18 years old) diagnosed with various types of cancer, who were under 40 years old when their children were diagnosed with the disease and are currently married The cases were selected in the age of pregnancy.

2- Control Group: this group includes mothers of children (less than 18 years old) not diagnosed with cancer, who were under 40 years old and married at the time their children were tested.

Sample Design: A random sample was chosen from the records of patients admitted for the first time in the Cairo University's NCI in 2009 taking into consideration that the mother's age is not over 40 years old at the time of child cancer diagnosis or testing (the year 2009). In this fashion, the selected groups were completed whether the group including children diagnosed with cancer or the other one including children not diagnosed with the disease as shown in graph 1. 


\section{Data Analysis Techniques /Methods}

The study relies on the advanced statistical analysis technique covering, according to the available data, certain key methods as follows:

- Alpha Cronbach's validity and reliability analysis to all the phrases in the questionnaire before and after examination or disease.

- Normality tests conducted on the 11 indicators which calculated from the data (Bernard Rosner 1982; Wayne W. Daniel)

- Hypotheses paired tests were conducted. In these tests, applied on the 11 indicators using the Wilcoxon signed-rank test, the significant differences between the post-diagnosis/testing and the pre-diagnosis/testing were examined.

The 11 indicators consist of the Likert Scale applied to all phases before and after examination or disease presented as follows: Mother professional condition (Working on a regular basis in the morning, Working full time, Your salary is adequate for satisfying all your family needs, either yours or others "husband, or any one responsible for the family", Annual reports reveal your high efficiency, Your efficiency at work is optimum, Work relationships are excellent) Willingness to bear children and family stability (I and my husband want to have children, I am psychologically stable, my husband is psychologically stable, all the family has a psychologically stable life, very limited relationships with our neighbors, There is time for family visits, we always go out for a picnic, The family does not bother itself) Husband professional condition (Mother professional condition phrase) Family recreational condition (The parent goes out with his friends once at least per week, The parent sits in the café at least once a week, All family members go out for family visits at least once a month, The family goes to the beach in one of the coasts, at least one of the family members goes to school, you go out to visit your neighbors at least once a week, you go out to visit your family at least once a month) Child health condition (the child's health status was very good, the child always visits doctors, run money was always spent on the child's sickness, When the child too kill, we took him/her to any governmental health facility for examination, When the child got sick, we took him to a specialist, When the child got sick, we took him to a mosque's /church's health center, When the child got sick, any member of the family goes to the pharmacist to gethim/her a treatment, Financial circumstances do not allow us to go to specialists for child diagnosis, Most of our money is consumed during the child's illness, Costs of child's tests and rays are OK, Cost of child's medications is OK, Costs of family's transportation are OK, Costs of residence are OK, female and male are even in health facility, The child whether boy or girl has the freedom to decide and choose the health care s/he receives)Child psychological condition(the child is always happy, the child is always lonely and tends to be secluded, the child is always crying, the child suffers from autism, the child's psychological status is always bad, the child is aggressive, the child is violent, the child is hyperactive) Child educational conditional (The child performs well in school, the child is so well organized in school, My children go to private /experimental schools, the cost of child's education is OK, the child participates in school activities, the child participates in athletic competitions, the child is studying with his colleagues, the child is distant learning at home, The child is taking private lessons at home, The child is taking private lessons in groups at school / outside home, The child likes education, The girl and boy are even in education) Child nutritional condition ("Does the child"eat vegetables at least once a week, eat 
fruits at least once a week, drink milk at least once a week, eat any meat at least once a week, eat chicken at least once a week, eat fish at least once a week, eat fast food at least once a week, drink soda at least once a week, eat three times per day, eat desserts (chocolate etc.) once a day; Costs of food are OK, The female and male are in eating well, The child whether male or female participates in decision about the food offered daily) Child recreational condition (There a baby sitter to take care of him/her, The child goes out for picnic at least once a year, the child goes out for camping at least once year, the child goes to the beach at least once year, the child goes to the club at least once a week, the child participates in sports activities, the child plays football with his friends in the street, the child goes to his friends' home or to the family's home to play, Costs of entertainment are OK, We play with our children at least once a week to entertain them, We go out with our children to entertain them, We don't buy clothes for the child except for some religious days and occasions such as starting school, The females and males participate in entertainment)Living standards related to family economic conditions(I had to borrow money, I had to sell properties (real estate, gold, cattle ...), I had to join saving group, I had to bid properties)Economic condition (evaluate your Economic condition- is it Very high - highMedium- low or very low).

- Explanatory Factor analysis applied for the new indicator composition of the 11 indicators before and after child examination or disease (DVID G.Kleinbanum ,Lawrencel. kupper 1978)

- K-Mean Cluster analysis used to classify the new two indicator which composite from the 11 indicators named as Family Status indicator before and the indicator after examination or disease. Ordinal logistic regression model analysis $\mathrm{Y}$ is the depended variable (levels of Family Status indicator) and X1, X2, are the independent variable, it will be presented in the model results. (Samir Ashor, Samia Abo El ftoh 2005).

\section{Results}

Patients admitted for the first time in the Cairo University's NCI in 2009was 22329, and the distribution of sample study is shown in graph 1 .

From the pilot study we find Alpha Cronbach factor of all indicator variables is verified. The factor of all phrases before illness or examination was 0.90 while the validity factor was 0.81. On the other hand, Alpha Cronbach factor of all phrases after illness or examination was 0.881 while the validity factor was 0.776 .

The data analysis results show that all the indicator non normal distribution as ShapiroWilk and Kolmogorov-Smirnova test showed in table 1 and there is a significant difference between averages of mothers' responses on their professional status before and after incidence and before and after examination, as well as the sample as a whole before and after. This average difference is unequal. $\mathrm{Z}$ value is greater than 1.96 which means that it lies in the refusal area. Thus, we refuse the null hypothesis (H0) that the averages are equal if $\mathrm{p}$-value significance is less than 0.05 . The indicator shows the deterioration of the professional status of the sample as a whole. In addition, it shows that the professional status of the affected mothers is more deteriorated than that of the unaffected 
mothers. The results also reveal decreased childbearing desire and family stability of the sample as a whole; especially the affected mothers compared to unaffected ones. Furthermore, the results show the deterioration of the husband's professional status in the whole sample, especially among the husbands of affected mothers more than those of unaffected mothers. As per results, recreation status of the sample families as a whole is deteriorated, especially among affected families more than the unaffected ones. The results show improvement in the health of unaffected children. On the contrary, the health of the affected children is deteriorated. In addition, psychological condition of the unaffected children improved, in comparison with the affected ones, respectively. The results indicate improvement of the educational level of sample children as a whole, especially as per the responses of the unaffected children's mothers more than the response of the affected mothers. Moreover, the results show the nutritional condition deterioration among the sample children as a whole; especially as per the answers of the affected children mothers compared to the unaffected mothers. Thus, we conclude the improvement or stability of the nutritional of the unaffected children. The recreational status of the sample children as a whole is improved, as per the answers of the unaffected children's mothers compared to the affected mothers. Also, results show the deterioration of the living conditions of the sample as a whole; as families widely tend to borrow, get loans, get indebted and sell their belongings, especially among the affected families. On the other hand, the results show that there is no difference between the average response of the unaffected children mothers; as it is clear that the living conditions before and after are the same, as shown in table 2.

A family status indicator was created using factor analysis of the abovementioned group of indicators (the professional status of the mother, the professional status of the husband, childbearing desires and family stability, family recreational status, child health condition, child psychological condition, child educational status, child nutritional condition, child recreational condition, family economic condition, family living conditions) before or after the illness or diagnosis.

The indicator is explained through four factors combined with two new variables: family status before the disease or examination and family status after the disease or examination as shown in Table 3,4,6,7

Afterwards, the cluster analysis was used to divide each variable by K-mean cluster method; as it divided each of the indicators into a family status of (low, medium, good), as shown in Tables 5, 8 .

The data analysis results show that there is a significant difference between averages of mothers' responses on their professional status before and after incidence and before and after examination, as well as the sample as a whole before and after. This difference is unequal. $\mathrm{Z}$ value is greater than 1.96 which means that it lies in the refusal area. Thus, we refuse the null hypothesis (H0) that the averages are equal if p-value significance is less than 0.05 .

The indicator shows the improvement of the sample family status as a whole as well as more improvement of the status of the families of the unaffected children compared to the families of the affected ones, as shown in Table 9. 
As for the results of the model, they revealed the following:

Statistical model parameters estimates for family status indicator before incidence or examination of the child

$\mathrm{Y}=$ Family status indicator before incidence (Good - medium - low) Reference Group - Level Good

$\mathrm{X} 1$ = Mother educational status (Never attended school - Elementary Education Secondary Education - University education- as a reference group)

$\mathrm{X} 2=$ Mother Work (Employed - Unemployed - as a reference group)

$\mathrm{X} 3=$ Husband educational status (Uneducated/Elementary Education - Secondary Education - University education- as a reference group)

$\mathrm{X} 4=$ Husband work (Permanent - Temporary $/$ Seasonal - as a reference group)

$\mathrm{X} 5=$ Mother age bracket (24-29, 30-34, 35-39, 40-45- as a reference group)

$\mathrm{X} 6=$ Husband age bracket (27-34, 35-39, 40-44, 45 and above - as a reference group)

$\mathrm{X} 7=$ Wealth indicator $($ Very poor - poor - medium - rich - very rich - as a reference group)

$\mathrm{X} 8=$ Child Sex (Male - Female - as a reference group)

$\mathrm{X} 10=$ Child order (First - Second - Third, more - as a reference group)

$\mathrm{X} 12=$ Residence environment (Urban - rural- as a reference group)

X13 $=$ Governorate (Urban Governorates - Lower Egypt - Frontier Governorate - Upper Egypt -as a reference group)

Model significance was about $24 \%$, however, results reveal, concerning the family status indicator before incidence, suggesting that there are other factors which affect family status before incidence that should be studied thoroughly.

The result of the test of parallelism- Hypothesis contains $-2 \log$-likelihood for the constrained model, the model that assumes the lines are parallel P-value $>0.0$ so we accept. The null hypothesis states that the location parameters (slope coefficients) are the same across response categories Pearson and Deviance measure for goodness of fit is significant in final model -2 log-likelihood at P-value $0.000<0.05$.

The results of Ordinal Logistic Regression Model Analysis of the determents of family status indicator (before incidence or examination) revealed that most factors included in the model are significant and have explain the factors at two cutoff value $(-1.777$ low level, 0.754 medium level).

We find significant factors at the two cutoff value like (mother work, Husband age, child order, Place of Residence (urban) with P-value less than 0.05, Odds ratio and parameter estimates shown in table10.

Statistical model parameters estimates for family status indicator after incidence or examination of the child

$\mathrm{Y}=$ Family status indicator after incidence (Good - medium - low) Reference Group Level Good 
$\mathrm{X} 1$ = Mother educational status (Uneducated - Elementary Education - Secondary Education - University education- as a reference group)

$\mathrm{X} 2=$ Mother Work (Employed - Unemployed - as a reference group)

$\mathrm{X} 3$ = Husband educational status (Never attended school/Elementary Education Secondary Education - University education- as a reference group)

$\mathrm{X} 4=$ Husband work (Permanent - Temporary /Seasonal - as a reference group)

$\mathrm{X} 5=$ Mother age bracket $(24-29,30-34,35-39,40-45-$ as a reference group)

X6 $=$ Husband age bracket (27-34, 35-39, 40-44, 45 and above - as a reference group)

$\mathrm{X} 7=$ Wealth indicator $($ Very poor - poor - medium - rich - very rich - as a reference group)

$\mathrm{X} 8=$ Child Status (Affected - unaffected - as a reference group)

$\mathrm{X} 9=$ Child Sex (Male - Female - as a reference group)

$\mathrm{X} 10=$ Child order (First - Second - Third, more - as a reference group)

$\mathrm{X} 11=$ Number of Family members (3-5, 5- more - as a reference group)

$\mathrm{X} 12=$ Child is alive or dead (Alive - Dead - as a reference group)

$\mathrm{X} 13=$ Residence environment (Urban - rural- as a reference group)

Model significance was about $65 \%$, however, results reveal, concerning the family status indicator after incidence, suggesting that there are other factors which affect family status before incidence that should be studied thoroughly.

The result of the test of parallelism- Hypothesis contains -2 log-likelihood for the constrained model, the model that assumes the lines are parallel P-value $>0.0$ so we accept. The null hypothesis states that the location parameters (slope coefficients) are the same across response categories, we find Pearson and Deviance measure goodness of fit is significant at final model $-2 \log$-likelihood is significant at P-value $0.000<0.05$.

The results of Ordinal Logistic Regression Model Analysis of the determents of family status indicator (after incidence or examination revealed that most factors included in the model are significant and have explain the factors at two cutoff value (-1.054 low level, 2.233 medium level).

We find significant factors at the two cutoff value like mother work and education, Husband age and work "permanent", child still alive or not, Place of Residence (urban) with P-value less than 0.05 and also find an important result that the child diagnosed with cancer insignificant factor. Odds ratio and parameter estimates shown in table 11.

\section{Conclusions}

Family Status Indicator is greatly affected especially when faced with a critical event, like when one of its children suffers from severe illness like cancer. In order to determine the changes that take place in that case, a questionnaire that includes all those data and a developed status indicator for pre and post suffering from the illness has to be conducted. In order to guarantee the validity of that questionnaire, it has been disseminated among healthy children tested negative of cancer, which show the great effect on the family status indicator as it is explained through this scientific paper. 
The results were showed that all the indicator non normal distributed. There were a significant difference between mean of mothers' answers on their professional status before and after incidence and before and after examination. This mean difference is unequal. $\mathrm{Z}$ value is greater than 1, 96 which means that it lies in the refusal area. Thus, we refuse the null hypothesis (H0) that the mean are equal if p-value significance is less than 0,05 . The indicator shows the deterioration of the professional status of the sample as a whole. In addition, it shows that the professional status of the affected mothers is more deteriorated than that of the unaffected mothers. The results also reveal decreased childbearing desire and family stability of the sample as a whole; especially the affected mothers compared to unaffected ones. Furthermore, the results show the deterioration of the husband's professional status in the whole sample, especially among the husbands of affected mothers more than those of unaffected mothers. As per results, recreation status of the sample families as a whole is deteriorated, especially among affected families more than the unaffected ones. The results show improvement in the health of unaffected children. On the contrary, the health of the affected children is deteriorated. In addition, psychological condition of the unaffected children improved, in comparison with the affected ones, respectively. The results indicate improvement of the educational level of sample children as a whole, especially as per the answers of the unaffected children mothers more than the answers of the affected mothers. Moreover, the results show the nutritional condition deterioration among the sample children as a whole; especially as per the answers of the affected children mothers compared to the unaffected mothers. Thus, we conclude the improvement or stability of the nutritional of the unaffected children. The recreational status of the sample children as a whole is improved, as per the answers of the unaffected children mothers compared to the affected mothers. Also, results show the deterioration of the living conditions of the sample as a whole; as families widely tend to borrow, get loans, get indebted and sell their belongings, especially among the affected families. On the other hand, the results show that there is no difference between the mean answers of the unaffected children mothers; as it is clear that the living conditions before and after are the same, as shown in table 2.

A family status indicator was created using factor analysis of the above mentioned group of indicators (the professional status of the mother, the professional status of the husband, childbearing desires and family stability, family recreational status, child health condition, child psychological condition, child educational status, child nutritional condition, child recreational condition, family economic condition, family living conditions) before or after the disease or examination.

The indicator is explained through four factors combined with two new variables: family status before the disease or examination and family status after the disease or examination as shown in Table 3,4,6,7.

Afterwards, the cluster analysis was used to divide each variable by K-mean cluster method; as it divided each of the indicators into a family status of (low, medium, good), as shown in Tables 5, 8 .

The data analysis results show that there is a significant difference between mean of mothers' answers on their professional status before and after incidence and before and after examination, as well as the sample as a whole before and after. This difference is unequal. $\mathrm{Z}$ value is greater than 1.96 which means that it lies in the refusal area. Thus, we 
refuse the null hypothesis $(\mathrm{H} 0)$ that the mean are equal if $\mathrm{p}$-value significance is less than 0.05 .

\section{Recommendations}

Family Status Indicator is greatly affected especially when faced with a critical event, like when one

The indicator shows the improvement of the sample family status as a whole as well as more improvement of the status of the families of the unaffected children compared to the families of the affected ones, as shown in Table 9.

As for the results of the model, they revealed the following:

Statistical model parameters estimates for family status indicator before incidence or examination of the child

$\mathrm{Y}=$ Family status indicator before incidence (Good - medium - low) Reference Group - Level Good

$\mathrm{X} 1$ = Mother educational status (Never attended school - Elementary Education Secondary Education - University education- as a reference group)

$\mathrm{X} 2=$ Mother Work (Employed - Unemployed - as a reference group)

$\mathrm{X} 3$ = Husband educational status (Uneducated/Elementary Education - Secondary Education - University education- as a reference group)

$\mathrm{X} 4=$ Husband work (Permanent - Temporary / Seasonal - as a reference group)

$\mathrm{X} 5=$ Mother age bracket $(24-29,30-34,35-39,40-45-$ as a reference group)

$\mathrm{X} 6=$ Husband age bracket $(27-34,35-39,40-44,45$ and above - as a reference group)

$\mathrm{X} 7=$ Wealth indicator $($ Very poor - poor - medium - rich - very rich - as a reference group)

$\mathrm{X} 8=$ Child Sex (Male - Female - as a reference group)

$\mathrm{X} 10=$ Child order (First - Second - Third, more - as a reference group)

$\mathrm{X} 12$ = Residence environment (Urban - rural - as a reference group)

X13 = Governorate (Urban Governorates - Lower Egypt - Frontier Governorate - Upper Egypt -as a reference group)

Model significance was about $24 \%$, however, results reveal, concerning the family status indicator before incidence, suggesting that there are other factors which affect family status before incidence that should be studied thoroughly.

The result of the test of parallelism- Hypothesis contains -2 log-likelihood for the constrained model, the model that assumes the lines are parallel P-value $>0.0$ so we accept The null hypothesis states that the location parameters (slope coefficients) are the same across response categories Pearson and Deviance measure for goodness of fit is significant in final model $-2 \log$-likelihood at P-value $0.000<0.05$.

The results of Ordinal Logistic Regression Model Analysis of the determents of family status indicator (before incidence or examination) revealed that most factors included in the model are significant and have explain the factors at two cutoff value $(-1.777$ low level, 0.754 medium level). 
We find significant factors at the two cutoff value like (mother work, Husband age, child order, Place of Residence (urban) with P-value less than 0.05, Odds ratio and parameter estimates shown in table 10.

Statistical model parameters estimates for family status indicator after incidence or examination of the child

$\mathrm{Y}=$ Family status indicator after incidence (Good - medium - low) Reference Group Level Good

$\mathrm{X} 1=$ Mother educational status (Uneducated - Elementary Education - Secondary Education - University education- as a reference group)

$\mathrm{X} 2=$ Mother Work (Employed - Unemployed - as a reference group)

$\mathrm{X} 3=$ Husband educational status (Never attended school/Elementary Education Secondary Education - University education- as a reference group)

$\mathrm{X} 4=$ Husband work (Permanent - Temporary / Seasonal - as a reference group)

$\mathrm{X} 5=$ Mother age bracket $(24-29,30-34,35-39,40-45$ - as a reference group)

$\mathrm{X} 6=$ Husband age bracket (27-34, 35-39, 40-44, 45 and above - as a reference group)

$\mathrm{X} 7=$ Wealth indicator $($ Very poor - poor - medium - rich - very rich - as a reference group)

$\mathrm{X} 8=$ Child Status (Affected - unaffected - as a reference group)

$\mathrm{X} 9=$ Child Sex (Male - Female - as a reference group)

$\mathrm{X} 10=$ Child order (First - Second - Third, more - as a reference group)

$\mathrm{X} 11=$ Number of Family members (3-5, 5- more - as a reference group)

$\mathrm{X} 12=$ Child is alive or dead (Alive - Dead - as a reference group)

$\mathrm{X} 13=$ Residence environment (Urban - rural - as a reference group)

Model significance was about $65 \%$, however, results reveal, concerning the family status indicator after incidence, suggesting that there are other factors which affect family status before incidence that should be studied thoroughly.

The result of the test of parallelism- Hypothesis contains -2 log-likelihood for the constrained model, the model that assumes the lines are parallel P-value $>0.0$ so we accept The null hypothesis states that the location parameters (slope coefficients) are the same across response categories, we find Pearson and Deviance measure goodness of fit is significant at final model $-2 \log$-likelihood is significant at P-value $0.000<0.05$.

The results of Ordinal Logistic Regression Model Analysis of the determents of family status indicator (after incidence or examination revealed that most factors included in the model are significant and have explain the factors at two cutoff value (-1.054 low level, 2.233 medium level).

We find significant factors at the two cutoff value like (mother work and education, Husband age and work "permanent", child still alive or not, Place of Residence (urban) with P-value less than 0.05 and also find an important result that the child diagnosed with cancer is significant factor. Odds ratio and parameter estimates shown in table 11. 


\section{Conclusion}

Family Status Indicator is greatly affected especially when faced with a critical event, like when one of its children suffers from unmerciful illness like cancer. In order to determine the changes that take place in that case, a questionnaire that includes all those data and a developed status indicator for pre and post suffering from the disease has to be conducted. In order to guarantee the validity of that questionnaire, it has been disseminated among healthy children tested negative of cancer, which show the great effect on the family status indicator as it is explained through this scientific paper.

\section{Recommendations}

Making in-depth study related to the factors that affect the child before suffering from the disease according to the family status indicator.

Making more studies that highlight the burden of disease (Dally).

Making more studies that highlight the economic burdens related to having a cancer child patient in the family.

\section{Annexes}

Graph 1 Sample study Patients admitted for the first time in the Cairo University's NCI in 2009

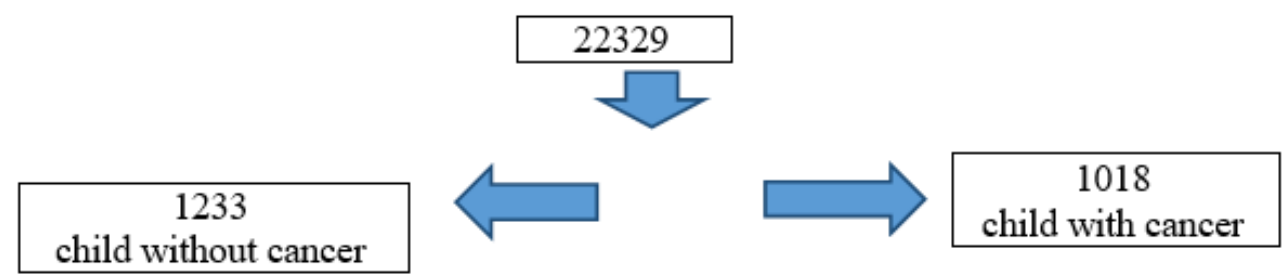

After phone calling to all the sample child mother less than 45 years

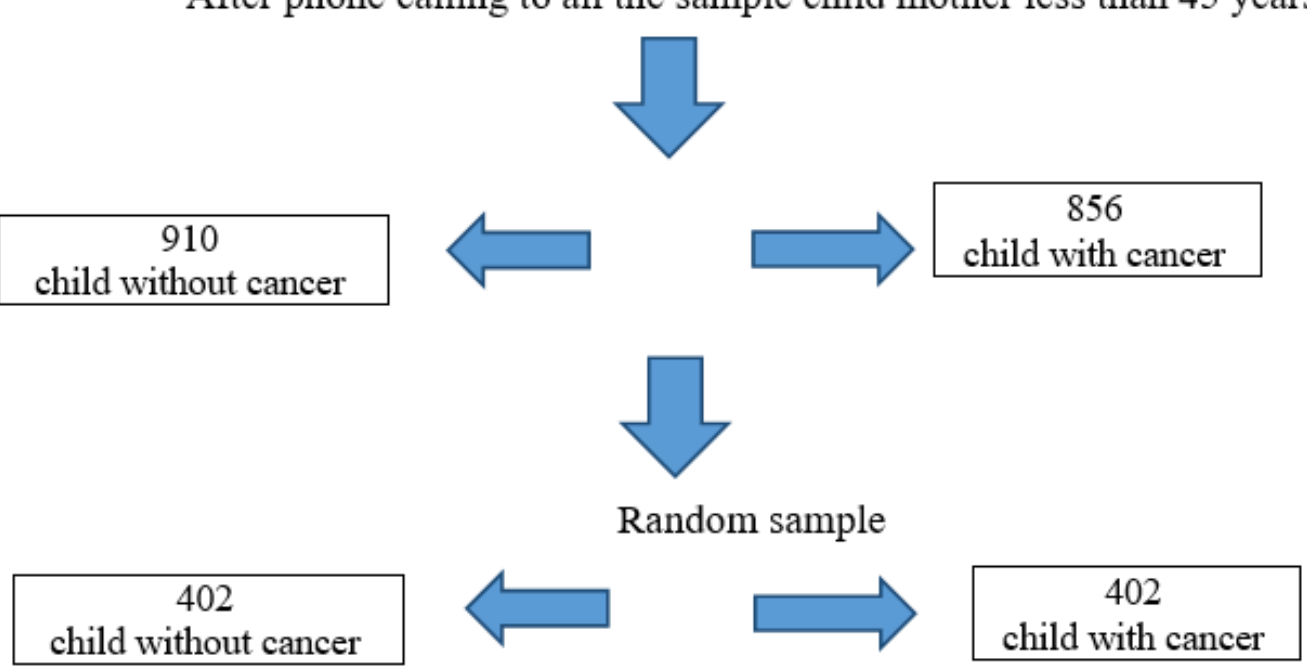


Table 1: Normality Test of the indicator components before - after child examination or disease

\begin{tabular}{|c|c|c|c|c|c|c|}
\hline \multirow{2}{*}{ The indicator components } & \multicolumn{3}{|c|}{ Kolmogorov-Smirnova } & \multicolumn{3}{|c|}{ Shapiro-Wilk } \\
\hline & Statistic & df & Sig. & Statistic & df & Sig. \\
\hline $\begin{array}{l}\text { Mother professional condition before child } \\
\text { examination or disease }\end{array}$ & 0.536 & 402 & 0.000 & 0.301 & 402 & 0.000 \\
\hline $\begin{array}{l}\text { Mother professional condition after child } \\
\text { examination or disease }\end{array}$ & 0.535 & 402 & 0.000 & 0.302 & 402 & 0.000 \\
\hline $\begin{array}{l}\text { Willingness to child bearing and family } \\
\text { stability before child examination or disease. }\end{array}$ & 0.131 & 402 & 0.000 & 0.969 & 402 & 0.000 \\
\hline $\begin{array}{l}\text { Willingness to child bearing and family } \\
\text { stability after child examination or disease. }\end{array}$ & 0.129 & 402 & 0.000 & 0.969 & 402 & 0.000 \\
\hline $\begin{array}{l}\text { Husband professional condition before child } \\
\text { examination or disease }\end{array}$ & 0.174 & 402 & 0.000 & 0.83 & 402 & 0.000 \\
\hline $\begin{array}{l}\text { Husband professional condition after child } \\
\text { examination or disease }\end{array}$ & 0.183 & 402 & 0.000 & 0.82 & 402 & 0.000 \\
\hline $\begin{array}{l}\text { Family recreational condition before child } \\
\text { examination or disease }\end{array}$ & 0.084 & 402 & 0.000 & 0.982 & 402 & 0.000 \\
\hline $\begin{array}{l}\text { Family recreational condition after child } \\
\text { examination or disease }\end{array}$ & 0.087 & 402 & 0.000 & 0.984 & 402 & 0.000 \\
\hline $\begin{array}{l}\text { Child health condition before examination or } \\
\text { disease }\end{array}$ & 0.083 & 402 & 0.000 & 0.981 & 402 & 0.000 \\
\hline $\begin{array}{l}\text { Child health condition after examination or } \\
\text { disease }\end{array}$ & 0.063 & 402 & 0 & 0.986 & 402 & 0.001 \\
\hline $\begin{array}{l}\text { Child psychological condition before } \\
\text { examination or disease }\end{array}$ & 0.361 & 402 & 0.000 & 0.73 & 402 & 0.000 \\
\hline $\begin{array}{l}\text { Child psychological condition after } \\
\text { examination or disease }\end{array}$ & 0.361 & 402 & 0.000 & 0.727 & 402 & 0.000 \\
\hline $\begin{array}{l}\text { Child educational conditional before } \\
\text { examination or disease }\end{array}$ & 0.356 & 402 & 0.000 & 0.758 & 402 & 0.000 \\
\hline $\begin{array}{l}\text { Child educational conditional after } \\
\text { examination or disease }\end{array}$ & 0.123 & 402 & 0.000 & 0.92 & 402 & 0.000 \\
\hline $\begin{array}{l}\text { Child nutritional condition before } \\
\text { examination or disease }\end{array}$ & 0.267 & 402 & 0.000 & 0.828 & 402 & 0.000 \\
\hline $\begin{array}{l}\text { Child nutritional condition after examination } \\
\text { or disease }\end{array}$ & 0.233 & 402 & 0.000 & 0.849 & 402 & 0.000 \\
\hline $\begin{array}{l}\text { Child recreational condition before } \\
\text { examination or disease }\end{array}$ & 0.093 & 402 & 0.000 & 0.974 & 402 & 0.000 \\
\hline $\begin{array}{l}\text { Child recreational condition after examination } \\
\text { or disease }\end{array}$ & 0.094 & 402 & 0.000 & 0.973 & 402 & 0.000 \\
\hline $\begin{array}{l}\text { Living standards related to family economic } \\
\text { conditions before child examination or } \\
\text { disease. Economic condition after child } \\
\text { disease }\end{array}$ & 0.175 & 402 & 0.000 & 0.905 & 402 & 0.000 \\
\hline $\begin{array}{l}\text { Living standards related to family economic } \\
\text { conditions after child examination or disease. } \\
\text { Economic condition after child disease }\end{array}$ & 0.168 & 402 & 0.000 & 0.903 & 402 & 0.000 \\
\hline Economic co & .4 & 804 & 0.000 & .640 & 804 & 0.000 \\
\hline Economic condition after child disease & .373 & 804 & .000 & .750 & 804 & 0.000 \\
\hline
\end{tabular}


Impact of Child's Cancer on Family Life Case Study: Children with Cancer Newly admitted to the National ......

Table 2: Paired tests- Wilcoxon of The indicator components after-before child examination or disease

\begin{tabular}{|c|c|c|c|c|}
\hline The indicator components & & $\begin{array}{c}\text { Total } \\
\text { sample }\end{array}$ & $\begin{array}{c}\text { sample with } \\
\text { cancer } \\
\text { cases }\end{array}$ & $\begin{array}{l}\text { sample without } \\
\text { cancer cases }\end{array}$ \\
\hline \multirow{2}{*}{$\begin{array}{l}\text { Mother professional condition } \\
\text { after-before child examination or } \\
\text { disease }\end{array}$} & $\mathrm{Z}$ ( test of significant) & $-6.038-b$ & $-5.236-b$ & $-3.069-b$ \\
\hline & Sig. (2-tailed) & 0.000 & 0.000 & 0.002 \\
\hline \multirow{2}{*}{$\begin{array}{l}\text { Willingness to child bearing and } \\
\text { family stability after -before child } \\
\text { examination or disease }\end{array}$} & $\mathrm{Z}$ ( test of significant) & $-18.211-b$ & $-17.359-b$ & $-4.976-b$ \\
\hline & Sig. (2-tailed) & 0.000 & 0.000 & 0.000 \\
\hline \multirow{2}{*}{$\begin{array}{l}\text { Husband professional condition } \\
\text { after- before child examination or } \\
\text { disease }\end{array}$} & $\mathrm{Z}$ ( test of significant) & $-18.724-b$ & $-15.099-b$ & $-11.167-b$ \\
\hline & Sig. (2-tailed) & 0.000 & 0.000 & 0.000 \\
\hline \multirow{2}{*}{$\begin{array}{l}\text { Family recreational condition after- } \\
\text { before child examination or disease }\end{array}$} & $\mathrm{Z}$ ( test of significant) & $-16.400-b$ & $-16.033-b$ & $-2.566-b$ \\
\hline & Sig. (2-tailed) & 0.000 & 0.000 & 0.010 \\
\hline \multirow{2}{*}{$\begin{array}{l}\text { Child health condition after- before } \\
\text { examination or disease }\end{array}$} & $\mathrm{Z}$ ( test of significant) & $-16.825-b$ & $-16.395-b$ & $-.118-\mathrm{b}$ \\
\hline & Sig. (2-tailed) & 0.000 & 0.000 & 0.906 \\
\hline \multirow{2}{*}{$\begin{array}{l}\text { Child psychological condition } \\
\text { after- before examination or } \\
\text { disease }\end{array}$} & $\mathrm{Z}$ ( test of significant) & $-16.609-b$ & $-16.421-b$ & $-.725-c$ \\
\hline & Sig. (2-tailed) & 0.000 & 0.000 & 0.468 \\
\hline \multirow{2}{*}{$\begin{array}{l}\text { Child educational conditional after- } \\
\text { before examination or disease }\end{array}$} & $\mathrm{Z}$ ( test of significant) & $-17.541-\mathrm{c}$ & $-10.307-c$ & $-13.480-\mathrm{c}$ \\
\hline & Sig. (2-tailed) & 0.000 & 0.000 & 0.000 \\
\hline \multirow{2}{*}{$\begin{array}{l}\text { Child nutritional condition after- } \\
\text { before examination or disease }\end{array}$} & $\mathrm{Z}$ ( test of significant) & $-14.759-b$ & $-14.786-b$ & $-1.212-b$ \\
\hline & Sig. (2-tailed) & 0.000 & 0.000 & 0.226 \\
\hline \multirow{2}{*}{$\begin{array}{l}\text { Child recreational condition after- } \\
\text { before examination or disease }\end{array}$} & $\mathrm{Z}$ ( test of significant) & $-12.235-\mathrm{c}$ & $-4.614-c$ & $-12.621-\mathrm{c}$ \\
\hline & Sig. (2-tailed) & 0.000 & 0.000 & 0.000 \\
\hline \multirow{2}{*}{$\begin{array}{l}\text { Living standards related to family } \\
\text { economic conditions after- before } \\
\text { child examination or disease. } \\
\text { Economic condition after child } \\
\text { disease }\end{array}$} & $\mathrm{Z}$ ( test of significant) & $-15.257-b$ & $-15.525-b$ & $-1.877-b$ \\
\hline & Sig. (2-tailed) & 0.000 & 0.000 & 0.061 \\
\hline \multirow{2}{*}{$\begin{array}{l}\text { Economic condition after- before } \\
\text { child disease }\end{array}$} & $\mathrm{Z}$ ( test of significant) & $-13.490-b$ & $-13.382-b$ & $-1.897-b$ \\
\hline & Sig. (2-tailed) & 0.000 & 0.000 & 0.058 \\
\hline
\end{tabular}

Wilcoxon Signed Ranks T - b Based on negative ranks - c based on positive ranks

Table 3: Factor Family Status Indicator before child examination or disease

\begin{tabular}{lccc}
\hline Factors & $\begin{array}{c}\text { Initial Eigenvalues- } \\
\text { Total }\end{array}$ & $\begin{array}{c}\% \text { of } \\
\text { Variance }\end{array}$ & Cumulative \% \\
\hline First factor & 1.993 & 18.115 & 18.115 \\
Second factor & 1.831 & 16.647 & 34.762 \\
Third factor & 1.762 & 16.016 & 50.778 \\
Forth factor & 1.198 & 10.889 & 61.666 \\
\hline
\end{tabular}


Table 4: (Component Matrix) before examination or disease Factor Family Status Indicator

\begin{tabular}{lcccc}
\hline & $\begin{array}{c}\text { First } \\
\text { factor }\end{array}$ & $\begin{array}{r}\text { Second } \\
\text { factor }\end{array}$ & $\begin{array}{c}\text { Third } \\
\text { factor }\end{array}$ & $\begin{array}{r}\text { Forth } \\
\text { factor }\end{array}$ \\
\hline $\begin{array}{l}\text { Child psychological condition before } \\
\text { examination or disease }\end{array}$ & 0.803 & -0.094 & -0.083 & 0.115 \\
$\begin{array}{l}\text { Child nutritional condition before } \\
\text { examination or disease }\end{array}$ & 0.744 & 0.12 & 0.259 & -0.074 \\
$\begin{array}{l}\text { Husband professional condition } \\
\text { before child examination or disease }\end{array}$ & 0.613 & 0.429 & 0.121 & -0.022 \\
$\begin{array}{l}\text { Child health condition before } \\
\text { examination or disease }\end{array}$ & 0.499 & -0.462 & 0.007 & -0.045 \\
$\begin{array}{l}\text { Willingness to child bearing and } \\
\text { family stability before child } \\
\text { examination or disease }\end{array}$ & -0.147 & 0.797 & -0.035 & -0.012 \\
$\begin{array}{l}\text { Family recreational condition before } \\
\text { child examination or disease }\end{array}$ & 0.302 & 0.741 & 0.083 & -0.063 \\
$\begin{array}{l}\text { Child recreational condition before } \\
\text { examination or disease }\end{array}$ & 0.092 & 0.148 & 0.882 & 0.022 \\
$\begin{array}{l}\text { Child educational conditional before } \\
\text { examination or disease }\end{array}$ & 0.053 & -0.08 & 0.88 & -0.049 \\
$\begin{array}{l}\text { Living standards related to family } \\
\text { economic conditions before child } \\
\text { examination or disease }\end{array}$ & 0.057 & -0.124 & -0.109 & 0.787 \\
$\begin{array}{l}\text { Mother professional condition before } \\
\text { child examination or disease }\end{array}$ & -0.071 & 0.033 & 0.022 & 0.588 \\
$\begin{array}{l}\text { Economic condition before child } \\
\text { disease }\end{array}$ & 0.19 & 0.428 & 0.317 & 0.452 \\
\hline
\end{tabular}

Table 5: Classification Family Status Indicator before child examination or disease

\begin{tabular}{lrrr}
\hline & \multicolumn{3}{c}{ Cluster } \\
\cline { 2 - 4 } & \multicolumn{1}{c}{$\mathbf{1}$} & $\mathbf{2}$ & $\mathbf{3}$ \\
Family Status Indicator before child examination or & 27.37 & 24.25 & 21.02 \\
disease & 199 & 391 & 214 \\
\hline
\end{tabular}

Table 6: Factor Family Status Indicator after child examination or disease

\begin{tabular}{|c|c|c|c|}
\hline Factors & Initial Eigenvalues- Total & $\begin{array}{r}\text { \% of } \\
\text { Variance }\end{array}$ & $\begin{array}{r}\text { Cumulative } \\
\% \\
\end{array}$ \\
\hline First factor & 2.569 & 23.352 & 23.352 \\
\hline Second factor & 1.865 & 16.955 & 40.307 \\
\hline Third factor & 1.539 & 13.989 & 54.296 \\
\hline Forth factor & 1.515 & 13.775 & 68.072 \\
\hline
\end{tabular}


Impact of Child's Cancer on Family Life Case Study: Children with Cancer Newly admitted to the National .....

Table 7: (Component Matrix) Factor Family Status Indicator after examination or disease

\begin{tabular}{llllll}
\hline & \multicolumn{4}{c}{ Component } \\
\cline { 2 - 5 } & First factor & Second factor & Third factor & Forth factor \\
\hline $\begin{array}{l}\text { Child health condition after } \\
\text { examination or disease. }\end{array}$ & 0.861 & 0.139 & -0.025 & 0.099 \\
$\begin{array}{l}\text { Child psychological condition after } \\
\text { examination or disease. }\end{array}$ & 0.823 & 0.011 & 0.085 & 0.019 \\
$\begin{array}{l}\text { Child nutritional condition after } \\
\text { examination or disease. }\end{array}$ & 0.68 & 0.442 & 0.144 & -0.053 \\
$\begin{array}{l}\text { Willingness to child bearing and } \\
\text { family stability after child } \\
\text { examination or disease. }\end{array}$ & 0.592 & -0.048 & 0.092 & 0.463 \\
$\begin{array}{l}\text { Child educational conditional after } \\
\text { examination or disease. }\end{array}$ & 0.187 & 0.887 & 0.128 & 0.049 \\
$\begin{array}{l}\text { Child recreational condition after } \\
\text { examination or disease. }\end{array}$ & 0.001 & 0.858 & 0.161 & 0.191 \\
$\begin{array}{l}\text { Husband professional condition } \\
\text { after child examination or disease. }\end{array}$ & 0.032 & 0.106 & 0.856 & 0.047 \\
$\begin{array}{l}\text { Family recreational condition after } \\
\text { child examination or disease. }\end{array}$ & 0.101 & 0.165 & 0.831 & 0.01 \\
$\begin{array}{l}\text { Living standards related to family } \\
\text { economic conditions after child } \\
\text { examination or disease. }\end{array}$ & 0.451 & -0.077 & 0.06 & 0.694 \\
$\begin{array}{l}\text { Economic condition after child } \\
\text { disease. }\end{array}$ & 0.206 & 0.27 & 0.154 & 0.683 \\
$\begin{array}{l}\text { Mother professional condition after } \\
\text { child examination or disease }\end{array}$ & -0.212 & 0.087 & -0.095 & 0.546 \\
\end{tabular}

Table 8: Classification Family Status Indicator after child examination or disease

\begin{tabular}{lrrr}
\hline & \multicolumn{3}{c}{ Cluster } \\
\cline { 2 - 4 } & 1 & 2 & 3 \\
\hline Family Status Indicator after child examination & 23.88 & 20.28 & 28.37 \\
or disease & 291 & 235 & 278 \\
case number & & \\
\hline
\end{tabular}

Table 9: Paired tests- Wilcoxon Family Status Indicator before and after child examination or disease

\begin{tabular}{lrrr}
\hline $\begin{array}{l}\text { Family Status Indicator after and } \\
\text { before child examination or disease }\end{array}$ & $\begin{array}{c}\text { Total } \\
\text { sample }\end{array}$ & $\begin{array}{l}\text { sample } \\
\text { with } \\
\text { cancer } \\
\text { cases }\end{array}$ & $\begin{array}{r}\text { sample } \\
\text { without } \\
\text { cancer cases }\end{array}$ \\
\hline Z ( test of significant) & $-5.145-\mathrm{C}$ & $-6.238-\mathrm{C}$ & $-13.884-\mathrm{C}$ \\
Asymp. Sig. (2-tailed) & 0.000 & 0.000 & 0.000 \\
\hline
\end{tabular}

Wilcoxon Signed Ranks T- c Based on positive ranks. 
Table 10: Impact of Demographic and socioeconomic determents on (FSI) before child examination or disease

\begin{tabular}{|c|c|c|c|c|}
\hline & Estimate & Wald & Sig. & Odds ratio \\
\hline Low-level & -1.777 & 17.446 & .000 & \\
\hline medium-level & .754 & 3.205 & .073 & \\
\hline \multicolumn{5}{|l|}{ Mother educational status } \\
\hline Uneducated & -.801 & 2.194 & .139 & 0.8073 \\
\hline Elementary Education & -.392 & .720 & .396 & 1.3047 \\
\hline Secondary Education & -.226 & .298 & .585 & 1.500 \\
\hline \multicolumn{5}{|l|}{ Mother work } \\
\hline Work & 2.105 & 43.154 & .000 & 0.736 \\
\hline \multicolumn{5}{|l|}{ Husband educational status } \\
\hline Uneducated/ Elementary Education & .075 & .035 & .852 & 0.4570 \\
\hline Secondary Education & -.661 & 3.498 & .061 & 1.0273 \\
\hline \multicolumn{5}{|l|}{ Husband work } \\
\hline Permanent & 178 & 1.037 & .309 & 0.7124 \\
\hline \multicolumn{5}{|l|}{ Mother age bracket } \\
\hline $24-29$ & -.320 & .773 & .379 & 0.7953 \\
\hline $30-34$ & -.445 & 2.823 & .093 & 4.6320 \\
\hline $35-39$ & -.523 & 5.387 & .020 & 3.5966 \\
\hline \multicolumn{5}{|l|}{ Husband age bracket } \\
\hline $27-34$ & -1.351 & 15.726 & .000 & 2.3655 \\
\hline $35-39$ & -1.007 & 16.857 & .000 & 1.1411 \\
\hline $40-44$ & -.805 & 13.988 & .000 & 0.9380 \\
\hline \multicolumn{5}{|l|}{ Wealth index } \\
\hline Very poor & .012 & .002 & .963 & 0.80977 \\
\hline Poor & -.114 & .225 & .635 & 0.5444 \\
\hline medium & -.185 & .598 & .439 & 0.3922 \\
\hline- rich & .469 & 4.277 & .039 & 1.3620 \\
\hline \multicolumn{5}{|l|}{ Child gender } \\
\hline Male & -.158 & 1.198 & .274 & 0.3616 \\
\hline \multicolumn{5}{|l|}{ Child order } \\
\hline the first / second & .751 & 18.243 & .000 & 1.3047 \\
\hline \multicolumn{5}{|l|}{ Residence environment } \\
\hline Urban & .511 & 9.246 & .002 & 1.1829 \\
\hline \multicolumn{5}{|l|}{ Place of Residence } \\
\hline Urban Governorates & .223 & .829 & .363 & 3.2059 \\
\hline Lower Egypt & -.079 & .232 & .630 & 0.4570 \\
\hline Frontier Governorate & 1.449 & 4.784 & .029 & 1.0273 \\
\hline
\end{tabular}


Table 11: Impact of Demographic and socioeconomic determents on ((FSI) after child examination or disease

\begin{tabular}{|c|c|c|c|c|}
\hline & Estimate & Wald & Sig. & Odds ratio \\
\hline Low-level & -1.054 & 3.474 & .062 & \\
\hline medium-level & 2.233 & 15.327 & .000 & \\
\hline \multicolumn{5}{|l|}{ Mother educational status } \\
\hline Uneducated & -1.647 & 6.478 & .011 & 0.1926 \\
\hline Elementary Education & -.943 & 2.849 & .091 & 0.3895 \\
\hline Secondary Education & -.730 & 2.082 & .149 & 0.48191 \\
\hline \multicolumn{5}{|l|}{ Mother work } \\
\hline Work & .950 & 7.597 & .006 & 2.5857 \\
\hline \multicolumn{5}{|l|}{ Husband educational status } \\
\hline Uneducated/ Elementary Education & .216 & .201 & .654 & 1.2411 \\
\hline Secondary Education & -.709 & 2.774 & .096 & 0.4921 \\
\hline \multicolumn{5}{|l|}{ Husband work } \\
\hline \multicolumn{4}{|l|}{ Mother age bracket } & 2.2728 \\
\hline $24-29$ & .334 & .628 & .428 & 1.396 \\
\hline $30-34$ & .346 & 1.273 & .259 & 1.413 \\
\hline $35-39$ & .145 & .305 & .581 & 1.156 \\
\hline \multicolumn{5}{|l|}{ Husband age bracket } \\
\hline $27-34$ & -1.196 & 9.432 & .002 & 0.3024 \\
\hline $35-39$ & -.973 & 11.539 & .001 & 0.3779 \\
\hline $40-44$ & -.781 & 9.867 & .002 & 0.4579 \\
\hline \multicolumn{5}{|l|}{ Wealth index } \\
\hline Very poor & .271 & .756 & .385 & 1.3112 \\
\hline Poor & .574 & 3.923 & .048 & 1.7753 \\
\hline medium & .498 & 2.944 & .086 & 1.6454 \\
\hline - rich & .466 & 3.175 & .075 & 1.5936 \\
\hline \multicolumn{5}{|l|}{ Child gender } \\
\hline Male & .049 & .086 & .770 & 1.0502 \\
\hline $\begin{array}{l}\text { Child order } \\
\text { the first / second }\end{array}$ & \multicolumn{3}{|c|}{ Child order } & 0.93239 \\
\hline \multicolumn{5}{|l|}{ Family number } \\
\hline $3-5$ one & -.032 & .031 & .861 & 0.9685 \\
\hline \multicolumn{5}{|l|}{ Child is alive or dead } \\
\hline $\begin{array}{l}\text { Still alive } \\
\text { Residence environment }\end{array}$ & 3.272 & 154.583 & .000 & 26.364 \\
\hline $\begin{array}{l}\text { Residence environment } \\
\text { Urban }\end{array}$ & .750 & 16.269 & .000 & 2.1170 \\
\hline $\begin{array}{l}\text { child diagnosed with cancer or not } \\
\text { Child with cancer }\end{array}$ & -3.416 & 221.662 & .000 & 0.0328 \\
\hline
\end{tabular}

-2 Log Likelihood (1014.5) Sig.0.000

Nagelkerke $\mathrm{R}^{2}(65 \%)$ 


\section{References}

1. Arslan, F. T., Basbakkal, Z. and Kantar, M. (2013). Quality of life and chemotherapy-related symptoms of Turkish cancer children undergoing chemotherapy. Asian Pacific J Cancer Prev, 14 (3), 1761-1768.

2. Ashore, S. and Abo Elftohe, S. (2005). SPSSWIN Advanced Applied Statistics.

3. Batalha, I. M., Fernandes, A. M. and Campos, C. (2015). Quality of life among children with cancer: agreement between child and parent reports. Journal of Esc. Anna Nery, 19(2).

4. Daniel, W. W. and Cross, C. L. (2013). Biostatistics: a foundation for analysis the health sciences, fourth edition .

5. Eiser C. and Associates, L. E. ( 2004). Children with cancer: the quality of life. Journal of the Canadian Academy of Child and Adolescent Psychiatry. 17(3), $161-162$.

6. Eiser, C., Eiser, J. R. and Stride, C. B. (2005). Quality of life in children newly diagnosed with cancer and their mothers. journal of Health and Quality of Life Outcomes, Biomed Central.

7. Harper, F. W., Goodlett, B. D., Trentacosta, C. J., Albrecht, T. L., Taub, J. W., Phipps, S. and Penner, L. A. (2014). Temperament, personality, and quality of life in pediatric cancer patients. J. Pediatr Psychol, 39(4), 459-68.

8. Hansson, H., Kjaergaard H, Johansen, C., Hallström, I., Christensen, J., Madsen, M. and Schmiegelow, K. (2013). Hospital based home care for children with cancer: feasibility and psychosocial impact on children and their families. Pediatr Blood Cancer, pubmed 244, 74.

9. Ibrahim, A. S., Mikhail, N. H., Khaled, H., Baraka, H., Abdeen , M., Bishara, A., Wahed, S. A. and Abdel Lateef, A. (2008). Cancer profile in Aswan. Egypt Methodology and Results Chart Book, 10.

10. kleinbaum, D. G. and kupper, L. (1978). Applied regression analysis and other multivariable methods. university of north Carolina at chapel hill.

11. Fawzy, M., Saleh, M., El-Wakil, M., Monir, Z. and Eltahlawy, E. (2013). Quality of life in Egyptian children with cancer. Journal of Cancer Therapy, 4, 1256-1261.

12. Rosner, B. (1982). Fundamentals of biostatistics. Harvard University, Duxbury Press Boston, Massachusetts.

13. Tas, F. and Y1lmaz, H. B. (2008). Quality of life concept in pediatric oncology patients. Asian Pacific Journal of Cancer Prevention Turk Onkoloji Dergisi, 23, 104-7.

14. Tremolada, M., Bonichini, S., Altoè, G., Pillon, M., Carli, M. and Weisner, T. S. (2011). Parental perceptions of health-related quality of life in children with leukemia in the second week after the diagnosis: a quantitative model. Support Care Cancer, 19, 591-8. 